\title{
Functionalized Syndiotactic Polystyrene Polymers Prepared by the Combination of Metallocene Catalyst and Borane Comonomer
}

\author{
J . Y. Dong, E. Manias, and T. C. Chung* \\ Department of Materials Science and Engineering, The Pennsylvania State University, \\ University Park, Pennsylvania 16802 \\ Received December 20, 2001; Revised Manuscript Received March 4, 2002
}

\begin{abstract}
This paper discusses an effective route in the functionalization of S-PS polymer that involves the direct copolymerization of styrene with a borane-containing styrenic monomer, i.e., 4-[B-(n-butylene)9-BBN ]styrene (B-styrene). The reactivity ratios of the two comonomers are quite close, with $r_{1}=0.9$ for styrene and $r_{2}=1.2$ for B-styrene in the $\mathrm{Cp} * \mathrm{Ti}(\mathrm{OMe})_{3} / \mathrm{MAO}$ catalyst system. A broad composition range of syndiotactic poly(styrene-co-B-styrene) copolymers has been prepared with narrow molecular weight and composition distributions. The random copolymer structure was further evidenced by DSC and ${ }^{13} \mathrm{C}$ NMR analyses. With increasing B-styrene concentration, the copolymers show a systematic decrease in glass transition temperature, melting point, crystallization temperature, and crystallinity. At above 8.4 mol \% B-styrene content, the crystallinity of the copolymer completely disappears. In turn, the borane groups in the copolymer are very versatile and can be quantitatively converted to other functional groups, such as hydroxy and anhydride groups, or transformed to free radical initiators for in situ free radical graft polymerization to prepare s-PS-g-PMMA graft copolymers.
\end{abstract}

\section{Introduction}

One of the most important advances in metallocene technology is the preparation of syndiotactic polystyrene (s-PS $)^{1}$ that exhibits high melting point $\left(\sim 270^{\circ} \mathrm{C}\right)$ and a relatively high crystallization rate that is several orders of magnitude ${ }^{2}$ faster than that in isotactic polystyrene (i-PS). s-PS is a novel engineering plastic made from an inexpensive commodity monomer.

Despite its unique properties, s-PS polymer also has several drawbacks that pose serious concerns in many commercial applications. Because of a high melting point, the required melt processing temperature at $>300$ ${ }^{\circ} \mathrm{C}$ (near the polymer decomposition temperature) causes a major problem in polymer processability. A modified s-PS polymer with a slightly reduced melting point (to about $250^{\circ} \mathrm{C}$ ) would be a very desirable material. In addition, s-PS polymer has poor impact strength and low surface energy, similar to traditional atactic polystyrene prepared by free radical and anionic processes. So far, there are only a few reports discussing the modification of s-PS polymer, including sulfonation ${ }^{3}$ and bromination ${ }^{4}$ of s-PS and hydroxylated s-PS 5 prepared via poly(styrene-co-4-tert-butyl dimethylsilyloxystyrene) precursor. Recently, Xu and Chung al so reported a new method using dialkylborane containing a $\mathrm{B}-\mathrm{H}$ group as a chain transfer agent during metal locene-mediated styrene polymerization to form borane-terminated syndiotactic polystyrene, ${ }^{6}$ which was further engaged in the free radical chain extension with methyl methacrylate (MMA) to form s-PS-b-PMMA diblock copolymers.

Several years ago, we devel oped a very useful method to functionalize polyolefins, such as polyethylene (PE) and polypropylene (PP), which involved direct copolymerization ${ }^{7}$ of $\alpha$-olefin and borane-containing $\alpha$-olefin by Ziegler-Natta and metallocene catalysts. Because of the excellent stability of borane moieties to catalysts and the good solubility of trialkylborane in hydrocarbon media, a broad range of borane-containing polyolefin

\footnotetext{
* To whom all correspondence should be addressed.
}

\section{Scheme 1}

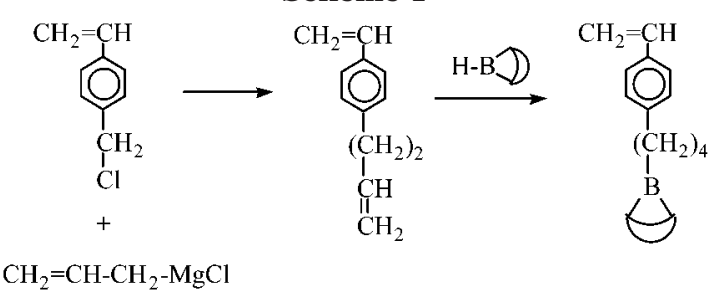

$\mathrm{CH}_{2}=\mathrm{CH}-\mathrm{CH}_{2}-\mathrm{MgCl}$

copolymers with uniform molecular structure were prepared without sacrificing catalyst activity. In addition, the incorporated borane groups in the polyolefin copolymers are very versatile and can be effectively interconverted to various functional groups under mild reaction conditions and also transferred to polymeric radicals for graft reactions ${ }^{8}$ to prepare polyol efin graft copolymers, such as PP-g-PM MA and PE-g-PMMA. We extended this borane monomer approach to s-PS to prepare functionalized s-PS polymers and s-PS graft copolymers that not only contain desirable functional groups but also have lower melting temperatures with improved processability.

\section{Results and Discussion}

Borane-Containing Monomer. As illustrated in Scheme 1, a new borane-containing monomer of 4-[B(n-butylene)-9-BBN ]styrene was prepared by a two-step reaction. After completing a coupling reaction between allylmagnesium chloride and vinyl benzyl chloride to form 4-(3-butenyl)styrene, containing a styrenic olefin and an $\alpha$-olefin groups, this resulting asymmetrical diene was selectively monohydroborated by $9-\mathrm{BBN}$ at the $\alpha$-olefinic double bond in an anti-Markovnikov manner.

Both reaction steps are very effective and produce high yields. Figure 1 compares the ${ }^{1} H$ NMR spectra of 4-[B-(n-butylene)-9-BBN]styrene (B-styrene) and 4-(3butenyl)styrene. After hydroboration reaction by a stoichiometric amount of 9-BBN, all the chemical shifts at 


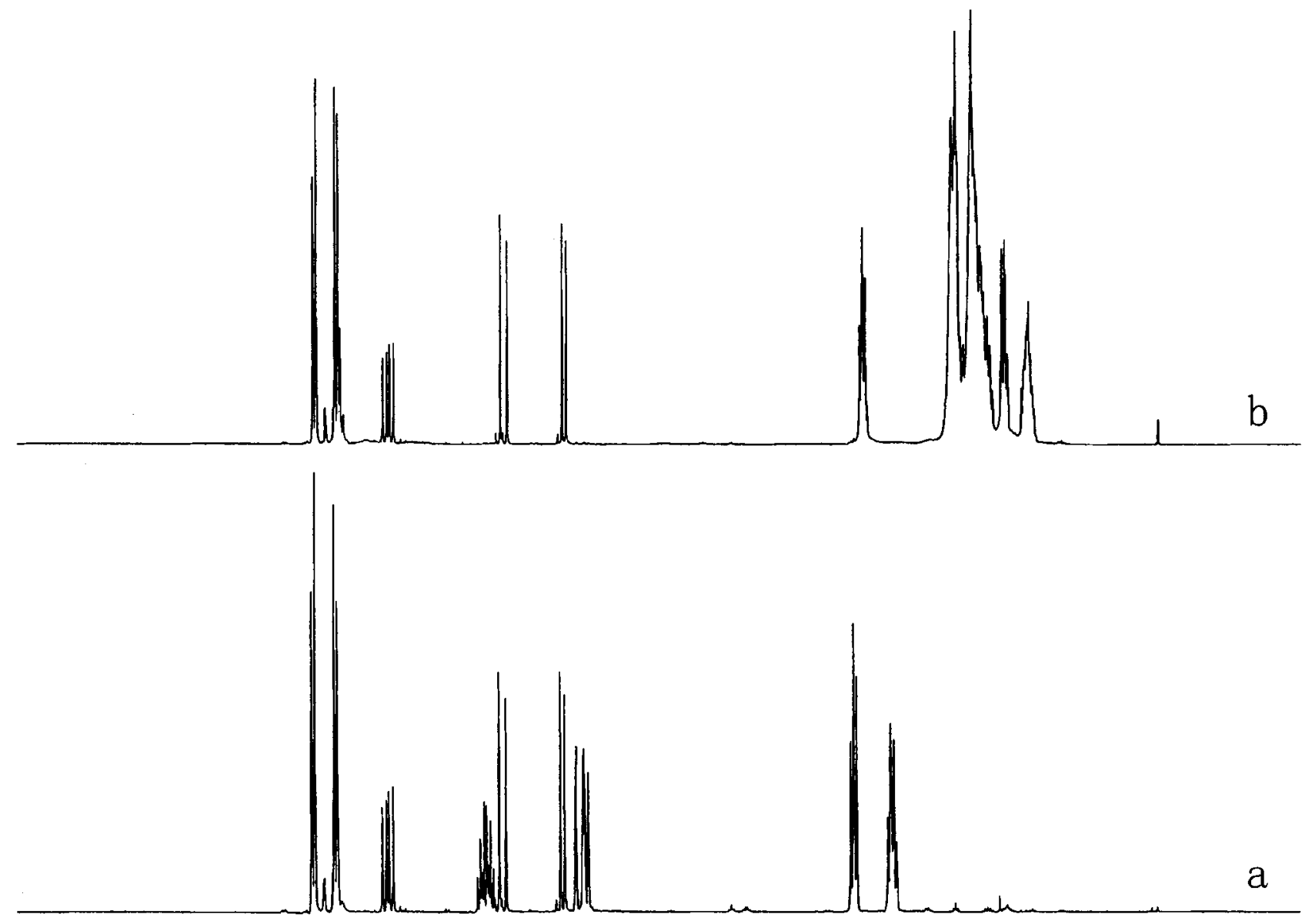

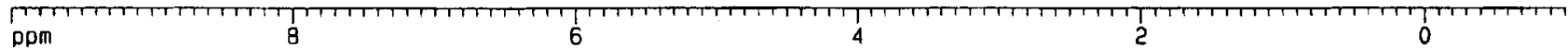

Figure 1. ${ }^{1} \mathrm{H}$ NMR spectra of (a) 4-(3-butenyl)styrene and (b) 4-[B-(n-butylene)-9-BBN]styrene (solvent: d-chlor oform).

Table 1. Copolymerization of Styrene (S) and 4-[B-(n-butylene)-9-BBN]styrene (B-S) with Syndiospecific Titanocene/ MAO Catalysts

\begin{tabular}{|c|c|c|c|c|c|c|c|c|c|c|}
\hline run no. & catalyst & $\begin{array}{c}\mathrm{B}-\mathrm{S} \text { in feed } \\
(\mathrm{mol} \%)\end{array}$ & $\begin{array}{c}{[\mathrm{S}]} \\
(\mathrm{mol} / \mathrm{L})\end{array}$ & $\begin{array}{l}{[\mathrm{B}-\mathrm{S}]} \\
(\mathrm{mol} / \mathrm{L})\end{array}$ & $\begin{array}{l}\text { yield } \\
\text { (g) }\end{array}$ & $\begin{array}{l}\text { catalyst } \\
\text { activity }^{b}\end{array}$ & $\begin{array}{l}\text { B-S content in } \\
\text { copolymer (mol \%) }\end{array}$ & $\begin{array}{c}M_{w} \times 10^{4} \\
(g / m o l)\end{array}$ & $\begin{array}{c}M_{n} \times 10^{4} \\
(g / m o l)\end{array}$ & $\begin{array}{c}\mathrm{PDI} \\
\mathrm{M}_{\mathrm{w}} / \mathrm{M}_{\mathrm{n}}\end{array}$ \\
\hline$A-1$ & $\mathrm{Cp} * \mathrm{Ti}(\mathrm{OMe})_{3}$ & 0 & 1.73 & 0 & 3.48 & 67.0 & 0 & 20.3 & 7.0 & 2.9 \\
\hline$A-2$ & $\mathrm{Cp} * \mathrm{Ti}(\mathrm{OMe})_{3}$ & 0.63 & 1.73 & 0.011 & 4.44 & 85.1 & 1.0 & 21.5 & 8.0 & 2.7 \\
\hline$A-3$ & $\mathrm{Cp} * \mathrm{Ti}(\mathrm{OMe})_{3}$ & 1.76 & 1.73 & 0.031 & 4.66 & 88.3 & 2.1 & 20.7 & 8.3 & 2.5 \\
\hline A-4 & $\mathrm{Cp} * \mathrm{Ti}(\mathrm{OMe})_{3}$ & 2.59 & 1.73 & 0.046 & 5.13 & 96.2 & 3.0 & 15.5 & 6.7 & 2.3 \\
\hline A-5 & $\mathrm{Cp} * \mathrm{Ti}(\mathrm{OMe})_{3}$ & 5.38 & 1.59 & 0.091 & 5.36 & 106.3 & 6.1 & 14.4 & 6.3 & 2.3 \\
\hline A-6 & Cp*Ti(OMe) $)_{3}$ & 7.16 & 2.14 & 0.165 & 6.73 & 97.3 & 8.4 & 12.7 & 5.5 & 2.3 \\
\hline A-7 & $\mathrm{Cp} * \mathrm{Ti}(\mathrm{OMe})_{3}$ & 12.2 & 2.04 & 0.284 & 6.04 & 86.7 & 16.7 & 9.8 & 5.2 & 2.0 \\
\hline A-8 & $\mathrm{Cp} * \mathrm{Ti}(\mathrm{OMe})_{3}$ & 24.3 & 1.13 & 0.363 & 2.98 & 66.7 & 32.2 & 5.3 & 2.8 & 2.0 \\
\hline A-9 & $\mathrm{Cp} * \mathrm{Ti}(\mathrm{OMe})_{3}$ & 100 & 0 & 0.730 & 1.91 & 87.3 & 100 & & & \\
\hline B-1 & $\mathrm{CpTiCl}_{3}$ & 6.10 & 1.41 & 0.091 & 3.52 & 78.2 & 6.7 & & & \\
\hline C-1 & $\mathrm{Cp}^{*} \mathrm{TiCl}_{3}$ & 6.10 & 1.41 & 0.091 & 2.98 & 66.2 & 5.4 & & & \\
\hline
\end{tabular}

a Polymerization conditions: [cat] $=100 \mu \mathrm{mol} / \mathrm{L}, \mathrm{Al} / \mathrm{Ti}=2000$, temperature $=50^{\circ} \mathrm{C}$, time $=3 \mathrm{~h}$, solvent $=40 \mathrm{~mL}$ of toluene. ${ }^{\mathrm{b}} \mathrm{In} \mathrm{kg}$ of polymer/mol $\mathrm{Ti} \cdot \mathrm{h} \cdot \mathrm{mol} / \mathrm{L}$.

2.44-2.58, 5.05-5.22, and 5.88-6.10 ppm (corresponding to the three type protons in $-\mathbf{C H}_{2}-\mathbf{C H}=\mathbf{C H}_{2}$ group) completely disappear. On the other hand, the chemical shifts at 5.30-5.37, 5.80-5.88, and 6.75-6.95 ppm (for the three methylene and methine protons in styrenic ol efin) are unchanged. The big difference in hydroboration reactivities between the two double bonds toward 9-BBN provides an effective route to the preparation of B-styrene monomer (I) without forming an undesirable dihydroborated product.

Copolymerization of Styrene with 4-[B-(n-butylene)-9-BBN]styrene. As illustrated in Scheme 2, the copolymerization of styrene and 4-[B-(n-butene)-9-BBN ]- styrene (B-styrene) was carried out with conventional half-sandwich metallocene catalysts, including $\mathrm{Cp}$ *Ti$(\mathrm{OMe})_{3} / \mathrm{MAO}, \mathrm{Cp}^{*} \mathrm{TiCl}_{3} / \mathrm{MAO}$, and $\mathrm{CpTiCl}_{3} / \mathrm{MAO}$ complexes $^{1}$ that exhibit high syndiospecificity and good catalyst activity in styrene polymerization. The resulting borane-containing copolymers, poly(styrene-co-4-[B(n-butylene)-9-BBN ]styrene) (II ), were completely soluble in tetrachloroethane at el evated temperature $\left(110^{\circ} \mathrm{C}\right)$. Some copolymers with high B-styrene comonomer contents (>8.4 mol \%) are soluble in toluene or THF at ambient temperature. ${ }^{11} \mathrm{~B}$ NMR spectra of all copolymers show a single chemical shift at 87 ppm (vs 


\section{Scheme 2}

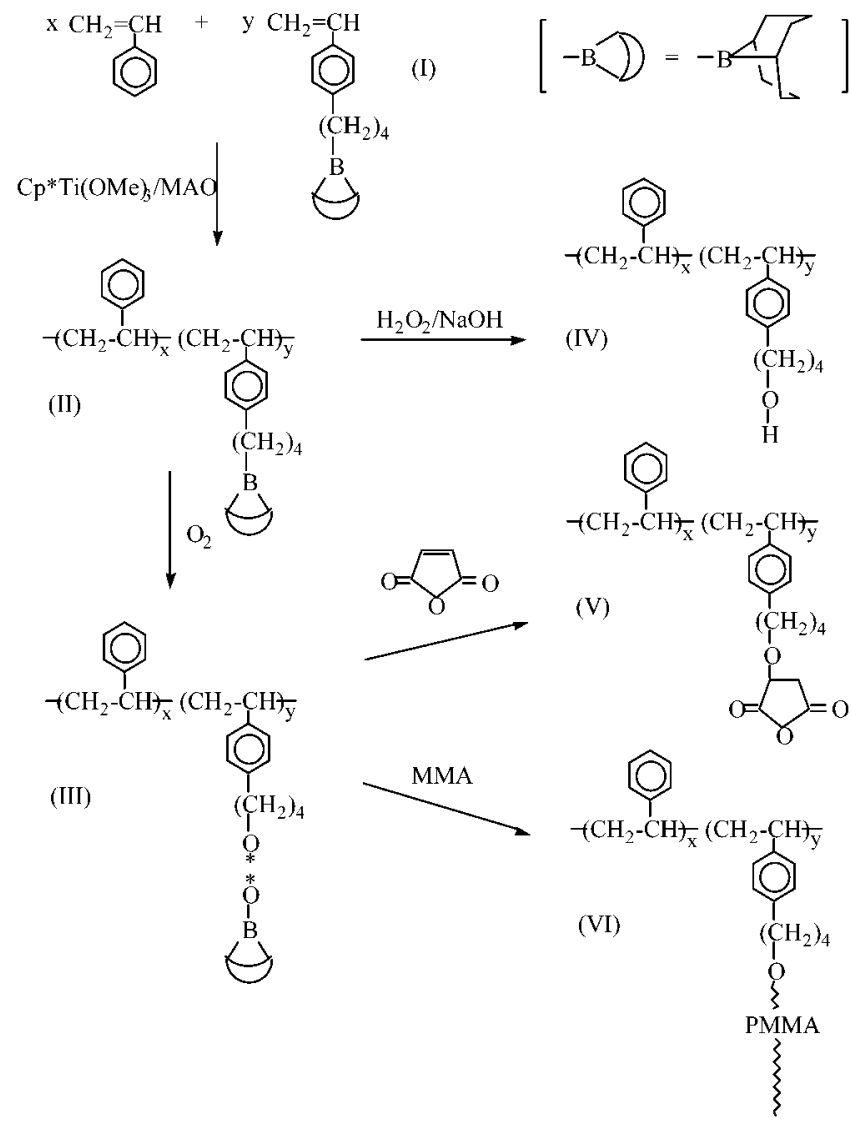

$\mathrm{BF}_{3} . \mathrm{OEt}_{2}$ ) corresponding to the pendant alky-9-BBN moieties.

Because of the oxygen sensitivity of the borane moiety, the borane-containing s-PS copolymers were usually oxidized by $\mathrm{NaOH} / \mathrm{H}_{2} \mathrm{O}_{2}$ to form the correspond-

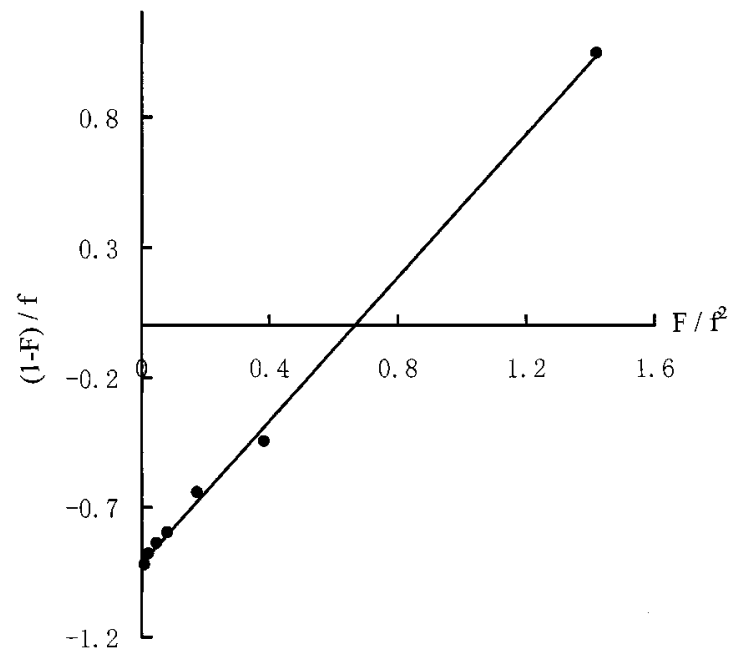

Figure 2. Fineman and Ross plots for copolymerization of styrene/B-styrene and the least-squares best-fit line ( $f=$ [styrene]/[B-styrene] in feed and $\mathrm{F}=\mathrm{d}[$ styrene]/d[B-styrene] mole ratio in polymer).

ing stable hydroxy-containing s-PS copolymers (s-PS$\mathrm{OH}$ ) for analysis. As will be discussed later, all of the transformation reactions were quantitative even in heterogeneous conditions. Table 1 summarizes the results of styrene/4-[B-(n-butylene)-9-BBN]styrene copolymerization reactions under various reaction conditions.

In general, both monomers show similar reactivity. The para-substituted borane group exhibits almost no effect on the monomer incorporation, which also indicates the unique advantages of trialkylborane moiety with excellent stability to the transition-metal catalysts and good solubility in hydrocarbon reaction media. The copolymer composition is basically controlled by the comonomer feed ratio, and we have prepared a whole composition range of styrene/B-styrene copolymers. In

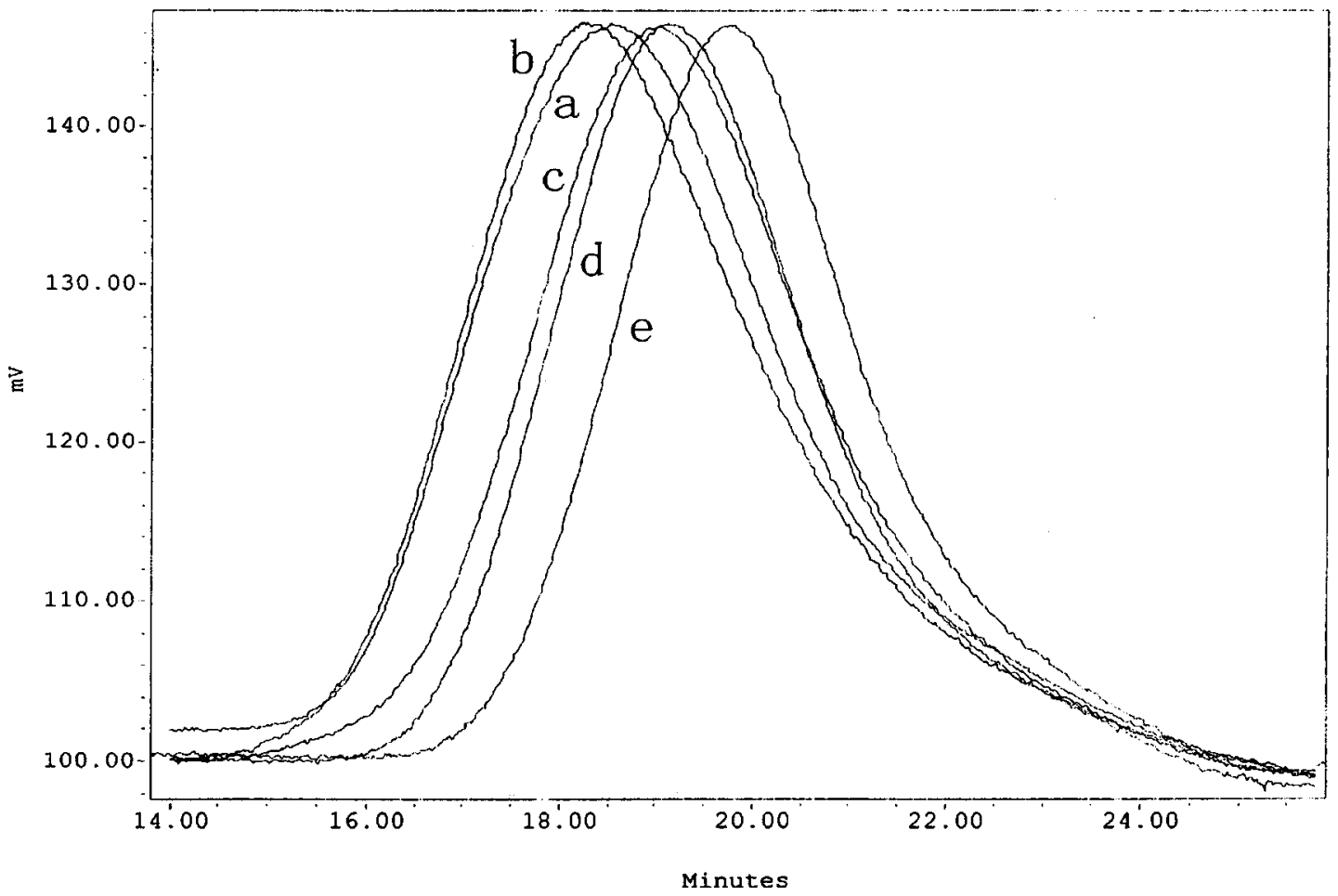

Figure 3. GPC curves of (a) s-PS homopolymer (A-1) and several styrene/B-styrene copolymers, including (b) A-2, (c) A-4, (d) $\mathrm{A}-5$, and (e) A-7 in Table 1 (solvent: trichlorobenzene; temperature: $135^{\circ} \mathrm{C}$ ). 


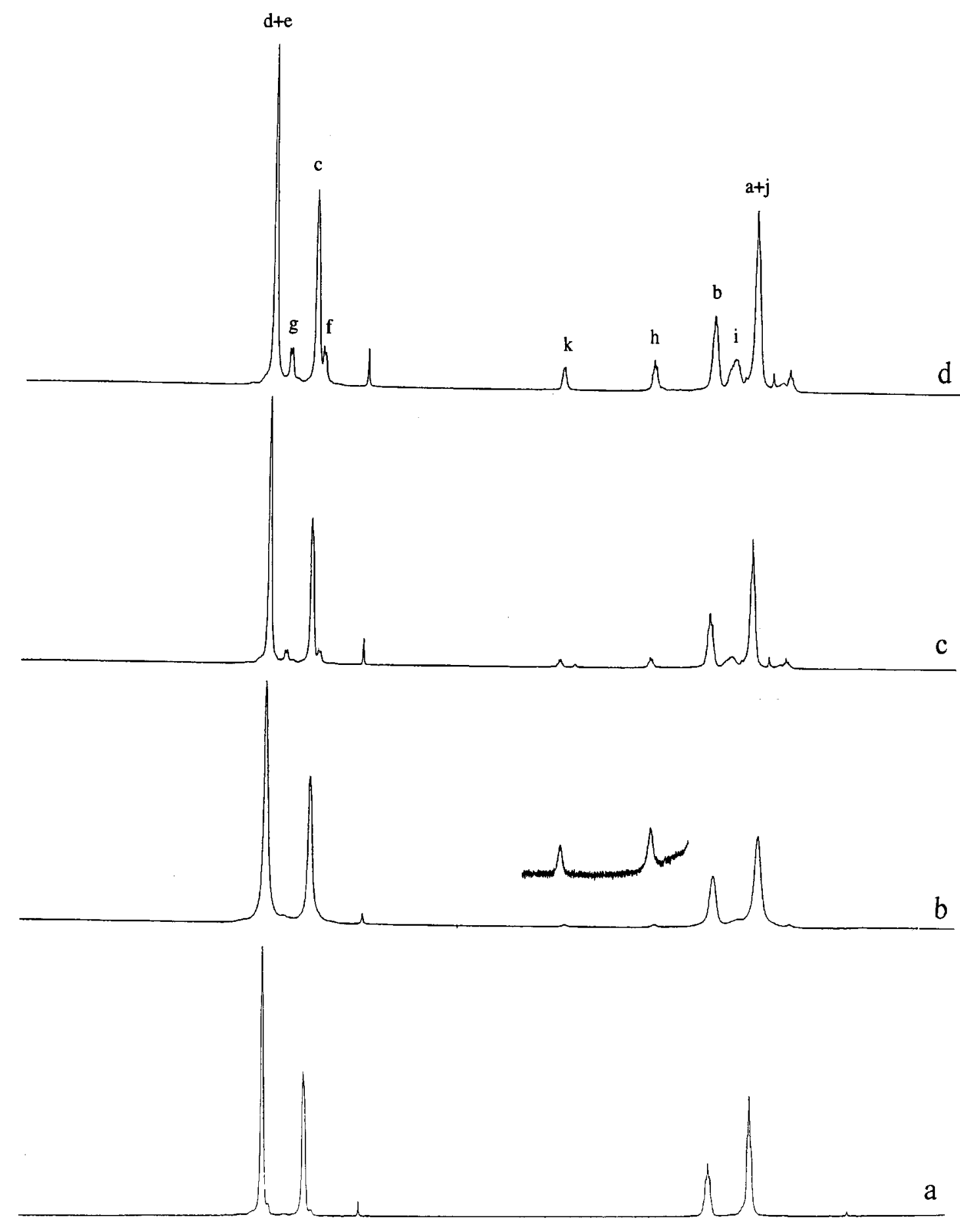

ppm

8

6

$T^{\top}$

Figure 4. ${ }^{1} \mathrm{H}$ NMR spectra of (a) s-PS and three s-PS-OH copolymers, containing (b) 2.1, (c) 8.4, and (d) $16.7 \mathrm{~mol} \%$ of $\mathrm{OH}$ groups (solvent: $\mathrm{C}_{2} \mathrm{D}_{2} \mathrm{Cl}_{4}$; temperature: $110^{\circ} \mathrm{C}$ ).

general, the catalyst efficiency in the copolymerization reaction increases somewhat compared to that of homopolymerization. The better diffusibility of monomers in the copolymer structures (due to lower crystallinity) may help provide better polymerization conditions.

The best way to investigate a copolymerization is to measure the reactivity ratio of the comonomers. A series of experiments were carried out by varying the monomer feed ratio and comparing the resulting polymer compositions at low conversion $(<10 \%)$. The reactivity ratios of styrene $\left(r_{1}=k_{11} / k_{12}\right)$ and B-styrene $\left(r_{2}=k_{22} / k_{21}\right)$ are estimated by the Fineman and Ross method. ${ }^{9}$ Figure 2 shows the plot $(1-F) / f$ vs $F / f^{2}$ and the least-squares best-fit line, where $\mathrm{f}=$ [styrene]/[B-styrene] in feed and $\mathrm{F}=\mathrm{d}[$ styrene]/d[B-styrene] mole ratio in polymer. The slope is $r_{2}$, and the extrapolation to $F / f^{2}=0$ gives $-r_{1}$. We obtain $r_{1}=0.9, r_{2}=1.2$, and $r_{1} r_{2}=1.08$ for styrene/ B-styrene copolymerization by a $\mathrm{Cp} * \mathrm{Ti}(\mathrm{OMe})_{3} / \mathrm{MAO}$ catalyst.

With $r_{1}$ and $r_{2}$ near 1 , this styrene/B-styrene copolymerization reaction is close to an ideal case. The copolymer obtained shall have a narrow composition 

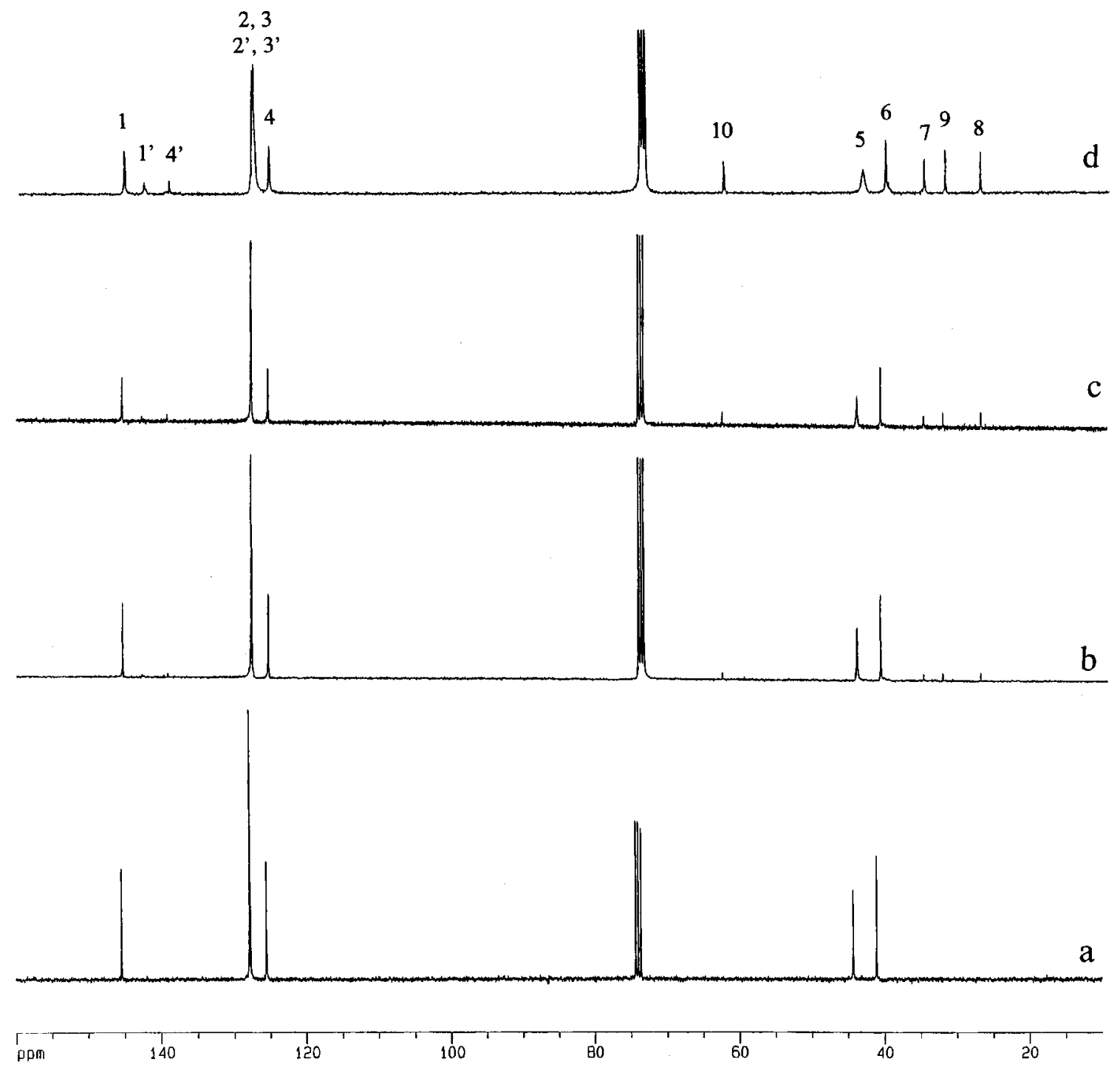

Figure 5. ${ }^{13} \mathrm{C}$ NMR spectra of (a) S-PS and three s-PS-OH copolymers, containing (b) 2.1 , (c) 8.4 , and (d) $16.7 \mathrm{~mol} \%$ of $\mathrm{OH}$ groups (solvent: $\mathrm{C}_{2} \mathrm{D}_{2} \mathrm{Cl}_{4}$; temperature: $110^{\circ} \mathrm{C}$ ).

distribution, and its composition shall be proportional to the monomer feed ratio, which are consistent with the DSC results (discussed later) and the experimental results shown in Table 1 (even with relatively long reaction time and high monomer conversion).

Figure 3 shows several GPC curves of the styrene/Bstyrene copol ymers (runs A-1, A-2, A-4, A-5, and A-7 in Table 1) prepared by the $\mathrm{Cp} * \mathrm{Ti}(\mathrm{OMe})_{3} / \mathrm{MAO}$ complex. The narrow molecular weight distribution in all samples, with $\bar{M}_{w} / \bar{M}_{n}=2-3$, implies that the polymerization follows a single-site reaction mechanism. In fact, the GPC curves show a slight reduction of molecular weight distribution in the copolymers, from $\bar{M}_{w} / \bar{M}_{n}=2.9$ in s-PS to 2.0 in styrene/B-styrene copolymers containing $32.2 \mathrm{~mol} \%$ of B-styrene. Similar narrow molecular distributions were also observed in the copolymers prepared by $\mathrm{Cp}^{*} \mathrm{TiCl}_{3} / \mathrm{MAO}$ and $\mathrm{CpTiCl} / \mathrm{MAO}$ complexes. The greater diffusibility of monomers in the copolymer structures (due to lower crystallinity) may also help provide the constant polymerization environment. In general, the copolymers exhibit high molecular weights that gradually decrease as the B-styrene content increases. However, they still maintain relatively high molecular weight $\left(\mathrm{M}_{\mathrm{w}}=53 \times 10^{3}\right.$ and $\mathrm{M}_{\mathrm{n}}=28 \times$
$10^{3} \mathrm{~g} / \mathrm{mol}$ ), even in the copolymer containing a very high concentration (32.2 mol \%) of B-styrene units.

Functionalized s-PS Polymers. The borane-containing copolymers are stable for long periods of time (6 months in a drybox) or at el evated temperatures (110 ${ }^{\circ} \mathrm{C}$ during NMR measurement) as long as $\mathrm{O}_{2}$ is excluded. In this study, the borane groups in the copolymers were oxidized by $\mathrm{NaOH} / \mathrm{H}_{2} \mathrm{O}_{2}$ reagents at $40^{\circ} \mathrm{C}$ for $3 \mathrm{~h}$. The borane groups were completely converted to the corre sponding hydroxy groups even under the heterogeneous conditions. The quantitative conversion under mild reaction conditions may be attributed to the combination of high reactivity and high surface area of borane groups in semicrystalline microstructure. Figures 4 and 5 compare the ${ }^{1} \mathrm{H}$ and ${ }^{13} \mathrm{C}$ NMR spectra of s-PS and three s-PS-OH copolymers containing 2.0, 8.4, and $16.0 \mathrm{~mol}$ $\%$ of $\mathrm{OH}$ groups, respectively.

In Figure 4, there are two aliphatic proton $\left(\mathrm{H}_{\mathrm{a}}\right.$ and $\mathrm{H}_{\mathrm{b}}$ ) peaks at 1.32 and $1.85 \mathrm{ppm}$ and two sharp aromatic proton $\left(\mathrm{H}_{\mathrm{c}}\right.$ and $\left.\mathrm{H}_{\mathrm{d}+\mathrm{e}}\right)$ peaks at 6.68 and $7.15 \mathrm{ppm}$ present in all compositions, indicating a high syndiotactic arrangement ${ }^{1}$ of styrene units in all of the polymers. The borane group in the B-styrene comonomer did not interfere with the syndiotactic incorporation of styrene in the polymerization reaction. With increasing hy- 


\section{Chart 1}
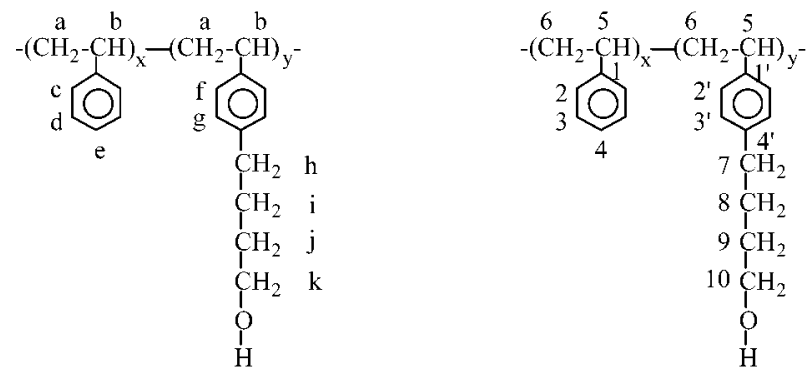

droxylated comonomer units, there are two new aromatic proton $\left(\mathrm{H}_{\mathrm{f}}\right.$ and $\left.\mathrm{H}_{\mathrm{g}}\right)$ peaks at 6.50 and $6.92 \mathrm{ppm}$ and two distinctive proton peaks at 2.55 and $3.68 \mathrm{ppm}$ corresponding to the protons $\left(\mathrm{H}_{\mathrm{h}}\right.$ and $\left.\mathrm{H}_{\mathrm{k}}\right)$ adjacent to the aromatic ring $\left(-\mathrm{CH}_{2}-\mathrm{Ph}\right)$ and the primary al cohol $\left(-\mathrm{CH}_{2}-\mathrm{OH}\right)$ in the hydroxylated B-styrene units. The combination of integrated intensities at 3.68 and 7.15 ppm and the corresponding protons in each chemical shift provides the copolymer composition (see Chart 1).

The stereostructure of the polymer was further examined by ${ }^{13} \mathrm{C}$ NMR. As shown in Figure 5 , all peaks are sharp and assigned to the corresponding carbon atoms in the polymer structures (shown in the inset). According to the literature, the presence of a single resonance ${ }^{10}$ for the substituted aromatic $C_{1}$ carbon in phenyl groups at 145.3 shows that these polymers are highly syndiotactic. The same conclusion can be reached by considering two $\mathrm{C}_{5}$ and $\mathrm{C}_{6}$ aliphatic carbons in the polymer backbone. Two sharp resonances at 44.5 and $41.0 \mathrm{ppm}$ correspond to the methine $C_{5}$ and methylene $\mathrm{C}_{6}$ in a highly stereoregular environment. In addition, a new resonance at $63.2 \mathrm{ppm}$ corresponds to the methylene carbon atom $\left(\mathrm{C}_{10}\right)$ in the $-\mathrm{CH}_{2}-\mathrm{OH}$ group. Overall, the sharp resonances in the copolymers resembles that of syndiotactic polystyrene and are very different from several reported atactic polystyrene derivatives containing chloro and methoxy groups ${ }^{11}$ prepared with other catalyst systems.

Figure 6 compares the DSC curves of s-PS homopolymer (A-1) and several s-PS-OH copolymers (runs A-2, A-3, A-5, A-6, A-7, and A-8 in Table 2). As expected, both the melting point $\left(T_{m}\right)$ and crystallinity $\left(\chi_{c}\right)$ of the copolymer are affected by the side chains. The higher the density of the side chain, the lower the $T_{m}$ and $\chi_{c}$. The detailed results of the melting point $\left(T_{m}\right)$ and crystallinity $\left(\chi_{c}\right)$ of the copolymers are summarized in Table 2 . The crystallinity $\left(\chi_{c}\right)$ of the copolymer was cal culated from fusion enthal py according to the following equation: $\chi_{c}=\mathrm{H}_{\mathrm{f}} / \mathrm{H}_{\mathrm{f}}{ }^{\circ} \times 100$, where $\mathrm{H}_{\mathrm{f}}$ and $\mathrm{H}_{\mathrm{f}}{ }^{\circ}$ (53 $\mathrm{J} / \mathrm{g})^{12}$ are the fusion enthal pies of the copolymer and the S-PS homopolymer, respectively. Sample A-3, with an average of 1 side chain per 50 styrene units, still possesses $>40 \%$ crystallinity with a sharp melting peak at $\mathrm{T}_{\mathrm{m}}=250{ }^{\circ} \mathrm{C}$. In addition to its functionality, this s-PS-OH copolymer may also benefit from better processability at $<300{ }^{\circ} \mathrm{C}$. The melting peak in the copolymer completely disappears at $>8.4 \mathrm{~mol} \%$ of B-styrene concentration. Only a single $T_{g}$ was observed throughout the whol e composition range, and the $T_{g}$ systematically decreases with increasing side-chain density. All of the experimental results indicate that the copolymer microstructure is homogeneous and that the copolymer morphology becomes completely amorphous with more than $8.4 \mathrm{~mol} \%$ of B-styrene units.

As illustrated in eq 2, the pending borane groups were selectively oxidized by oxygen to form polymeric radicals

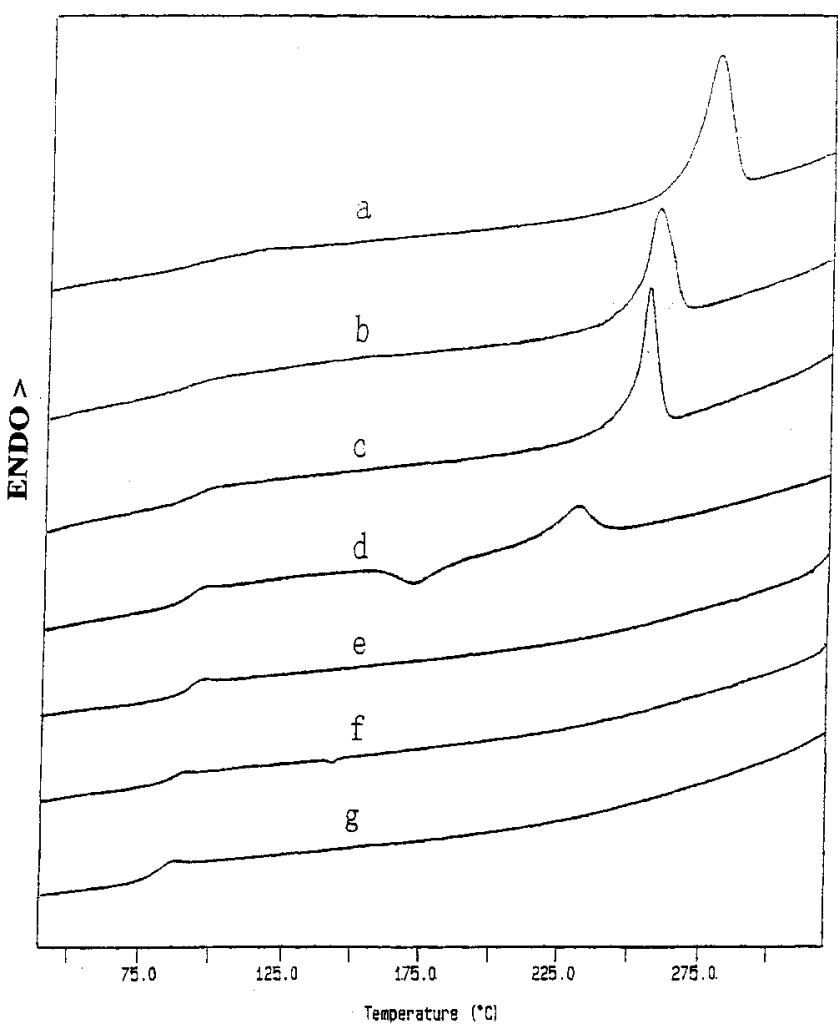

Figure 6. DSC curves of (a) S-PS homopolymer and several s-PS-OH copolymers, containing (b) 1.0, (c) 2.1, (d) 6.1, (e) 8.4, (f) 16.7 , and (g) $32.2 \mathrm{~mol} \%$ of $\mathrm{OH}$ groups.

(III) that are associated with "stable" borinate radicals. ${ }^{8}$ The polymeric radicals react in situ with maleic anhydride (MA) to produce maleic anhydride grafted s-PS (s-PS-g-MA) (V) with a single MA unit in each side chain. Figure 7 shows the IR spectrum of a s-PS-g-MA copolymer containing $8 \mathrm{~mol} \%$ of MA units, and the inset compares the absorption region of the $v_{\mathrm{C}=0}$ vibration modes between s-PS and three s-PS-g-MA copolymers with 1, 3, and 8 mol \% MA contents, respectively.

After the MA graft reaction, several new absorption peaks were observed at 1860 and $1780 \mathrm{~cm}^{-1}$ corresponding to two $v_{\mathrm{C}=\mathrm{O}}$ vibrational stretching modes $^{13}$ in succinic anhydride. A high concentration of MA groups has been incorporated in the s-PS copolymers that is similar to that of the incorporated borane units. The concentration of incorporated MA units was calculated by a standard industrial method (discussed in the Experimental Section), which is based on the IR carbonyl group absorption intensity and sample thickness.

s-PS Graft Copolymers. The pending stable polymeric radicals associated with dormant borinate radicals in the s-PS copolymer (III) are very useful in the preparation of s-PS graft copolymers. In the presence of MMA monomers, the free radical graft polymerization results in s-PS-g-PMMA (VI) graft copolymers. The molecular weight of the incorporated PMMA side chain is proportional to the MMA monomers used, and the graft density is governed by the incorporated borane content.

After the graft reaction, the product, isolated by filtration and washed with boiling $\mathrm{MeOH}$, was then extracted with acetone in a Soxhlet apparatus for $24 \mathrm{~h}$ to remove PMMA homopolymer ( $<10 \%)$. Figure $8 \mathrm{com}$ pares the ${ }^{1} \mathrm{H}$ NMR spectra of a starting styrene/Bstyrene copolymer containing $1 \mathrm{~mol} \% \mathrm{~B}$-styrene units (after hydroxylation) and two corresponding S-PS-g- 
Table 2. A Summary of the Thermal Properties ${ }^{\mathrm{a}}$ of Hydyoxylated s-PS Copolymers

\begin{tabular}{ccccccc}
\hline entry & $\mathrm{OH}-$ content (mol \%) & $\mathrm{T}_{\mathrm{g}}\left({ }^{\circ} \mathrm{C}\right)$ & $\mathrm{T}_{\mathrm{m}}\left({ }^{\circ} \mathrm{C}\right)$ & $\mathrm{T}_{\mathrm{c}}^{\mathrm{b}}\left({ }^{\circ} \mathrm{C}\right)$ & $\Delta \mathrm{H}(\mathrm{g} / \mathrm{g})$ & $\chi_{\mathrm{c}}^{\mathrm{c}}(\%)$ \\
\hline A-1 & 0 & 101.5 & 272.5 & 233.1 & 30.1 & 56.8 \\
A-2 & 1.0 & 97.6 & 263.0 & 226.9 & 26.8 & 50.5 \\
A-3 & 2.1 & 94.1 & 250.1 & 208.7 & 21.9 & 20.2 \\
A-4 & 3.0 & 93.1 & 247.2 & 197.7 & 38.1 \\
A-5 & 6.1 & 87.8 & 223.9 & ND & 16.6 \\
A-6 & 8.4 & 87.9 & ND & ND & 31.3 \\
A-7 & 16.7 & 81.3 & ND & ND & \\
A-8 & 32.2 & 79.8 & ND & ND &
\end{tabular}

${ }^{a}$ Based on DSC measurement with heating and cooling rate of $20{ }^{\circ} \mathrm{C} / \mathrm{min} .{ }^{\mathrm{b}}$ Crystallization temperature. ${ }^{\mathrm{c}} \mathrm{Crystallinity} .{ }^{\mathrm{d}} \mathrm{ND}=$ not detected.

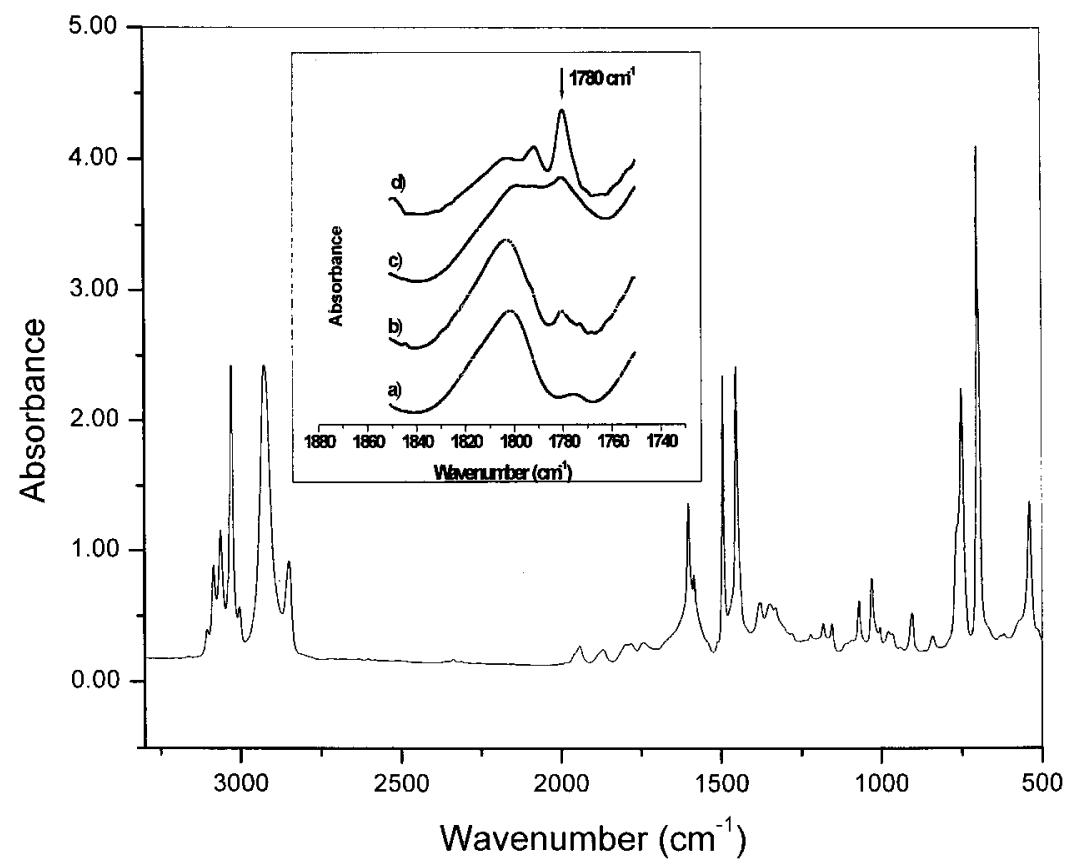

Figure 7. IR spectrum of a s-PS-g-MA copolymer containing $8 \mathrm{~mol} \%$ of MA units. The inset compares the absorption region of $v_{\mathrm{C}=\mathrm{O}}$ vibration modes between (a) S-PS and three s-PS-g-MA copolymers with (b) 1, (c) 3, and (d) 8 mol \% MA content.

PMMA graft copolymers with 20 and $59 \mathrm{~mol} \%$ MMA contents, respectively. In addition to the major peaks at $1.32,1.85,6.65$, and 7.15 ppm for the protons in s-PS backbone, the distinctive peak at 3.58 ppm corresponds to methoxyl groups $\left(\mathrm{CH}_{3}-\mathrm{O}\right)$ in PMMA.

\section{Experimental Details}

Instrumentation and Materials. All room- and hightemperature ${ }^{1} \mathrm{H} N M R$ and ${ }^{13} \mathrm{C} N \mathrm{NMR}$ spectra were recorded on a Bruker AM-300 spectrometer. Fourier transform infrared spectroscopy was performed on a Bio-Rad instrument using polymer thin film. The molecular weight was determined using a Waters $150 \mathrm{C}$ that was operated at $135^{\circ} \mathrm{C}$. The columns used were mStyragel HT of $10^{6}, 10^{5}, 10^{4}$, and $10^{3} \AA$. A flow rate of $0.7 \mathrm{~mL} / \mathrm{min}$ was used, and the mobile phase was trichlorobenzene. Narrow molecular weight distribution polystyrene samples were used as standards. Differential scanning calorimetry (DSC) was measured (with a heating rate of $20^{\circ} \mathrm{C} / \mathrm{min}$ ) on a Perkin-EImer DSC-7, TAC-7 instrument controller.

All $\mathrm{O}_{2^{-}}$and moisture-sensitive manipulations were performed inside an argon-filled drybox equipped with a dry train. $\mathrm{Cp} * \mathrm{Ti}(\mathrm{OMe})_{3}(95 \%), \mathrm{Cp}^{*} \mathrm{TiCl}_{3}(97 \%), \mathrm{CpTiCl}_{3}$ (97\%), MAO (10 wt \% in toluene), and allylmagnesium chloride (2.0 M in THF) were purchased from Aldrich and used without further purification. 9-BBN (0.5 M in THF) from Callery Chemical Co. was used as received. Styrene (>99\%) and vinylbenzyl chloride (90\%) from Aldrich were dried over $\mathrm{CaH}_{2}$ before distillation. $\mathrm{CP}$ grade toluene was deoxygenated by argon purge before refluxing for $48 \mathrm{~h}$ and then distilled over sodium.

Synthesis of 4-[B-(n-butylene)-9-B BN]styrene. 4-[B-(nbutylene)-9-BBN ]styrene monomer was prepared by a two-step reaction process. The first step of the coupling reaction between allylmagnesi um chloride and vinylbenzyl chloride was carried out in a $1000 \mathrm{~mL}$ flask equipped with a magnetic stirring bar and inert atmosphere. In the flask, $200 \mathrm{~mL}$ of allylmagnesium chloride/THF solution (2 M) was diluted with $150 \mathrm{~mL}$ of THF, and then $50 \mathrm{~mL}$ of 4-vinylbenzyl chloride $(0.35 \mathrm{~mol})$ diluted with $50 \mathrm{~mL}$ of THF was added dropwise with stirring and cooling to maintain the reaction temperature at $0{ }^{\circ} \mathrm{C}$. The reaction mixture was slowly warmed to room temperature and maintained at room temperature for another $2 \mathrm{~h}$ before adding $100 \mathrm{~mL}$ of water to destroy the excess allylmagnesium chloride. The solution was then poured into $500 \mathrm{~mL}$ of water, and the organic layer was separated and dried over anhydrous sodium sulfate. After removing the THF solvent, about $46 \mathrm{~g}$ of the resulting 4-(3-butenyl)styrene was distilled over calcium hydride under reduced pressure (about 25 Torr) at $60^{\circ} \mathrm{C}$ with about $83 \%$ yield.

The selective mono-hydroboration of 4-(3-butenyl)styrene by 9-BBN $(0.3 \mathrm{~mol})$ was carried out in THF $(300 \mathrm{~mL})$ at room temperature. An equal amount $(600 \mathrm{~mL})$ of $9-B B N(0.5 \mathrm{M}$ in THF ) was added dropwise into 4-(3-butenyl)styrene/THF solution over a period of $4 \mathrm{~h}$. After another $1 / 2 \mathrm{~h}$ of stirring at room temperature, the THF solvent was vacuum-removed. The reaction mixture was subjected to vacuum distillation (5 Torr) at $110{ }^{\circ} \mathrm{C}$ to obtain about $70 \mathrm{~g}$ of 4-[B-(n-butylene)-9-BBN]styrene with $90 \%$ yield. The ${ }^{1} \mathrm{H}$ NMR spectrum (shown in Figure 1) confirms the molecular structure.

Copolymerization of Styrene and 4-[B-(n-butylene)9-BBN]styrene. The copolymerization reactions were carried out in an argon-filled drybox. In a typical reaction (run 3 in Table 1 ), $20 \mathrm{~mL}$ of styrene and $0.86 \mathrm{~g}$ of B-styrene were mixed with $100 \mathrm{~mL}$ of anhydrous toluene in a $250 \mathrm{~mL}$ flask under a 

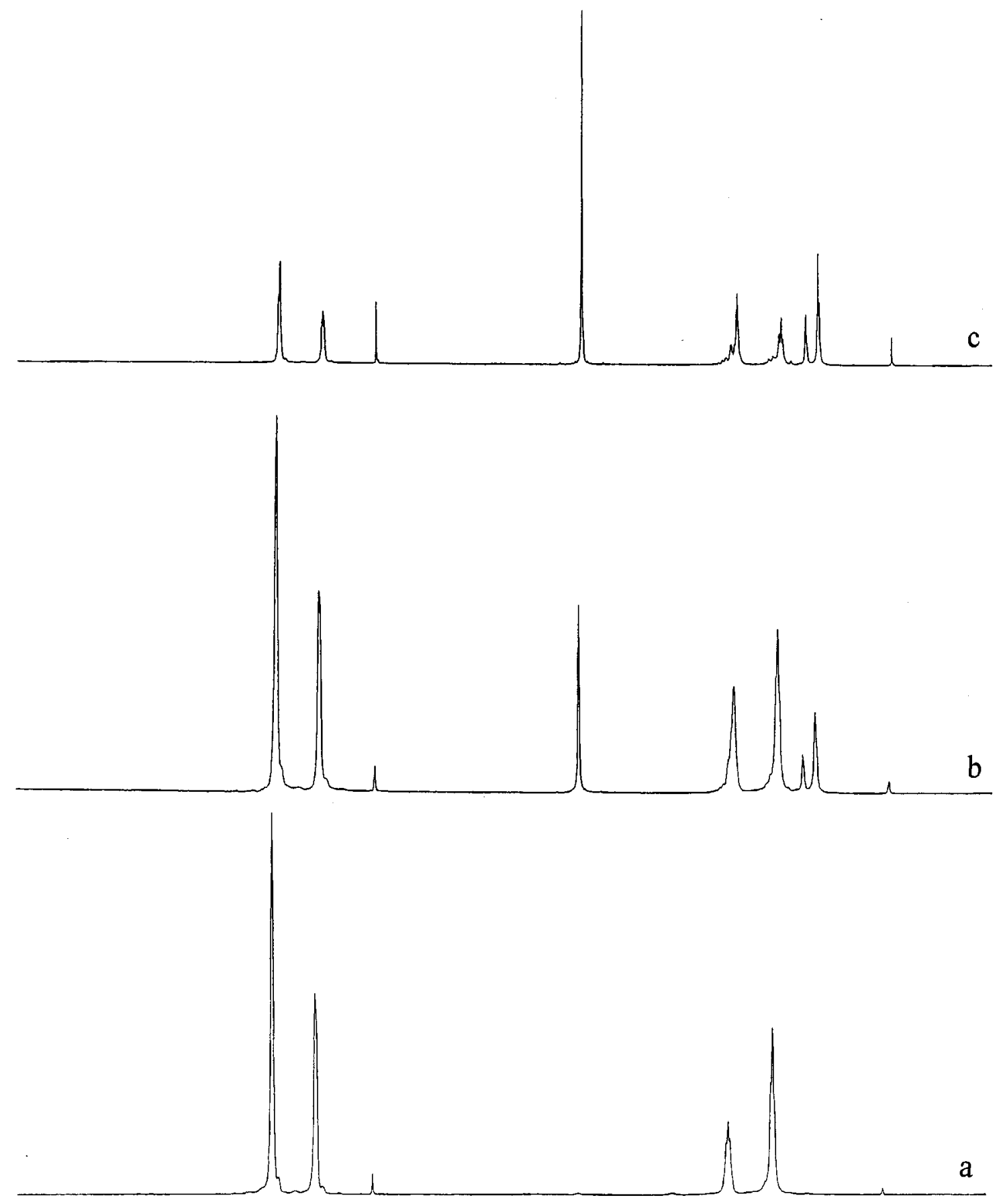

pom

Figure 8. ${ }^{1 \mathrm{H}} \mathrm{NMR}$ spectra of (a) s-PS-OH containing $1 \mathrm{~mol} \% \mathrm{OH}$ units and two corresponding s-PS-g-PMMA graft copolymers with (b) 20 and (c) 59 mol \% MMA contents.

nitrogen atmosphere. $11 \mathrm{~mL}$ of MAO (10 wt \% in toluene) was added with stirring. The copolymerization reaction was started by adding $1 \mathrm{~mL}(10 \mu \mathrm{mol})$ of $\mathrm{Cp} * \mathrm{Ti}(\mathrm{OMe})_{3} /$ toluene solution. The polymerization was carried out at $50{ }^{\circ} \mathrm{C}$ for $3 \mathrm{~h}$ before terminating with $100 \mathrm{~mL}$ of IPA. The precipitated copolymer was isolated and washed with IPA and dried under vacuum to yield $4.66 \mathrm{~g}$ of polymer solid.

Hydroxylation Reaction. Under a nitrogen atmosphere, the powder form of styrene/B-styrene copolymer $(3 \mathrm{~g})$ containing $2.1 \mathrm{~mol} \%$ B-styrene was suspended in $50 \mathrm{~mL}$ of $\mathrm{THF}$ solvent in a $200 \mathrm{~mL}$ flask equipped with a mechanical stirrer. Oxidation reaction was carried out by adding $\mathrm{NaOH} / \mathrm{H}_{2} \mathrm{O}_{2}$ solution $\left(\mathrm{B} / \mathrm{NaOH} / \mathrm{H}_{2} \mathrm{O}_{2}=1 / 2 / 3\right)(0.06 \mathrm{~g})$ and $5 \mathrm{~mL}$ of methanol at $0{ }^{\circ} \mathrm{C}$. The reaction mixture was warmed to $40{ }^{\circ} \mathrm{C}$ for $4 \mathrm{~h}$.
The polymer was isolated by precipitation in $\mathrm{MeOH}$. The polymer was refluxed in $\mathrm{MeOH}$ for $1 \mathrm{~h}$ before removing residual boric acid by distillation of the $\mathrm{B}(\mathrm{OH})_{3} / \mathrm{MeOH}$ azeotrope. The polymer was isolated by filtration and dried under vacuum to obtain $2.7 \mathrm{~g}$ of hydroxylated s-PS copolymer. The ${ }^{1} \mathrm{H}$ NMR spectrum shown in Figure $4 a$ indicates a quantitative conversion of borane to hydroxy groups.

Maleic Anhydride Reaction. In a $150 \mathrm{~mL}$ flask equipped with a stirrer and $\mathrm{N}_{2}$ atmosphere, $3 \mathrm{~g}$ of styrene/B-styrene copolymer containing $3.0 \mathrm{~mol} \%$ of B-styrene was suspended in $50 \mathrm{~mL}$ of THF along with $5 \mathrm{~g}$ of maleic anhydride. Under stirring, a stoichiometric quantity of oxygen (vs borane) was slowly added to the suspended polymer solution at ambient temperature. After $2 \mathrm{~h}$, the mal eation reaction was terminated 
by precipitating the polymer mixture in 2-propanol. The maleated s-PS product $(2.8 \mathrm{~g})$ was isolated by filtration and purified by Soxhlet extraction with acetone for $24 \mathrm{~h}$ before drying the resulting polymer under vacuum.

The MA concentration in the polymer was estimated with

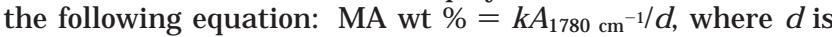
the film thickness, $A_{1780 \mathrm{~cm}^{-1}}$ is the peak absorbency, and $\mathrm{k}$ is the absorption constant for anhydride. The $\mathrm{k}$ constant is determined by calibration of the known compounds, assuming the absorption constant is independent of the incorporated MA structures.

Graft Reaction of s-PS with PMMA. In nitrogen atmosphere, $3 \mathrm{~g}$ of s-PS-B copolymer containing $1 \mathrm{~mol} \% \mathrm{~B}$-styrene units suspended in $30 \mathrm{~mL}$ of THF solvent was mixed with $6 \mathrm{~g}$ of MMA monomer in a septum-capped $250 \mathrm{~mL}$ flask equipped with a magnetic stirring bar. Under agitation, a stoichiometric quantity (15 mL) of oxygen (vs borane) was slowly added to the suspended polymer solution. The graft polymerization was allowed to proceed at room temperature for $12 \mathrm{~h}$ before exposing the solution to air. The suspended polymer solution was poured into $200 \mathrm{~mL}$ of acetone, then filtered, and washed with acetone several times. The isolated polymer was extracted with boiling THF to remove PMMA homopolymer. The insoluble fraction (soluble in 1,1,2,2-tetrachloroethane, 1,2,4trichlorobenzene at elevated temperatures) is s-PS-g-PMMA graft copolymer $(7.3 \mathrm{~g})$. The ${ }^{1} \mathrm{H}$ NMR spectrum of the graft copolymer shown in Figure 8c indicates $59 \mathrm{~mol} \%$ MMA content.

\section{Conclusion}

This paper has shown a facile route in the preparation of functional s-PS polymers and s-PS graft copolymers. The chemistry involves a new 4-[B-(n-butylene)-9-BBN]styrene (B-styrene) comonomer and half-sandwich metal locene catal ysts. The reactivity ratios near to 1 in the two monomers allow the preparation of a broad composition range of s-PS copolymers with narrow molecular weight and composition distributions. The pending borane groups in the copolymer not only provide the desirable functional groups, such as hydroxy and anhydride, but also reduce the melting temperature of
s-PS to the manageable processing temperature and still maintain high crystallinity. In addition, the pending borane groups were also transformed to stable radicals for graft-from polymerization to prepare s-PS-g-PMMA graft copolymers.

Acknowledgment. The authors thank the National Institute of Standards and Technology for its financial support.

\section{References and Notes}

(1) (a) Ishihara, N.; Seimiya, T.; Kuramoto, M.; Uoi, M. Macromolecules 1986, 19, 2464. (b) Thayer, A. M. Metallocene Catalysts I nitiate New Era In Polymer Synthesis. Chem. Eng. News 1995, 11, 1-20. (c) Ishihara, N.; Kuramoto, M.; Uoi, M. Eur. Patent, EP 210615, 1987; Chem. Abst. 106:177084P. (d) Chien, J . C. W.; Salajka, Z. J. Polym. Sci., Part A 1991, 29, 1253. (e) Xu, G. Macromol ecules 1998, 31, 586

(2) Ishihara, N. Macromol. Symp. 1995, 89, 553.

(3) Orler, E. B.; Moore, R. B. Macromolecules 1994, 27, 4774.

(4) Liu, S.; Sen, A. Macromolecules 2000, 33, 5106.

(5) Kim, K. H.; J o, W. H.; Kwak, S.; Kim, K. U.; Kim, J. Macromol. Rapid Commun. 1999, 20, 175.

(6) Xu, G.; Chung, T. C. Macromolecules 1999, 25, 8689.

(7) (a) Chung, T. C. Macromolecules 1988, 21, 865. (b) Chung, T. C.; Rhubright, D. Macromolecules 1993, 26, 3019. (c) Xu, G.; Chung, T. C. J. Am. Chem. Soc. 1999, 121, 6763. (d) Chung, T. C.; Xu, G.; Lu, Y.; Hu, Y. Macromolecules 2001 34, 8040.

(8) (a) Chung, T. C.; J iang, G. J . Macromolecules 1992, 25, 4816 (b) Chung, T. C.; J anvikul, W.; Bernard, R.; J iang, G. J . Macromolecules 1994, 27, 26. (c) Chung, T. C.; Lu, H. L.; J anvikul, W. J . Am. Chem. Soc. 1996, 118, 705. (d) Chung, T. C. Prog. Polym. Sci. 2002, 27, 39.

(9) Fineman, M.; Ross, S. D. J . Polym. Sci. 1950, 5, 259.

(10) Ishihara, N.; Kuramoto, M.; Uoi, M. Macromolecules 1988 21,3356

(11) Grassi, A.; Longo, P.; Proro, A.; Zambelli, A. Macromolecules 1989, 22, 104

(12) De Candia, F.; Filho, A. R.; Vittoria, V. Colloid Polym. Sci. 1991, 269, 650.

(13) Lu, B.; Chung, T. C. Macromolecules 1998, 31, 5943.

MA012215E 